\title{
Emended Description of Buttiauxella agrestis with Recognition of Six New Species of Buttiauxella and Two New Species of Kluyvera: Buttiauxella ferragutiae sp. nov., Buttiauxella gaviniae sp. nov., Buttiauxella brennerae sp. nov., Buttiauxella izardii sp. nov., Buttiauxella noackiae sp. nov., Buttiauxella warmboldiae sp. nov., Kluyvera cochleae sp. nov., and Kluyvera georgiana sp. nov.
}

HANS E. MÜLLER, ${ }^{1 *}$ DON J. BRENNER, ${ }^{2}$ G. RICHARD FANNING, ${ }^{3}$ PATRICK A. D. GRIMONT, ${ }^{4}$ AND PETER KÄMPFER ${ }^{5} \dagger$

Staatliches Medizinaluntersuchungsamt, D-38124 Braunschweig, ${ }^{1}$ and Fachgebiet Hygiene, Technische Universität, D-13353 Berlin ${ }^{5}$ Germany; Emerging Bacterial and Mycotic Diseases Branch, National Center for Infectious Diseases, Centers for Disease Control and Prevention, Atlanta, Georgia 303332; Division of Biochemistry, Walter Reed Army Institute of Research, Washington, D.C. 20307-51003; and Unité des Enterobactéries, Institut National de la Santé et de la Recherche Médicale Unité 389, Institut Pasteur, F-75724 Paris Cedex 15, France ${ }^{4}$

\begin{abstract}
A total of 219 strains belonging to the genera Buttiauxella and Kluyvera were studied; 171 of these strains were isolated from mollusks, mainly snails and slugs, obtained from around the world. On the basis of DNA-DNA hybridization data, the strains were grouped into 11 genomospecies. A total of 44 phenotypic characters were used to differentiate the genera Buttiauxella and Kluyvera at the genus level and to identify genomospecies. There were significantly higher phenotypic probability distances between the genomospecies in the genus Buttiauxella and the genomospecies in the genus Kluyvera than between the genomospecies in the same genus. Therefore, the existence of Buttiauxella and Kluyvera as different genera was confirmed. The existence of new species necessitated broadening the definitions of both genera. In two cases, two Buttiauxella species could not be quantitatively differentiated biochemically, and several other pairs of species could be separated only by the results of one biochemical test. Nonetheless, combinations of several characteristics were used to differentiate all of the species with levels of certainty ranging from $\log 10.79$ to $\log 57.77$ (calculated as probability distances). The following new species are proposed: Buttiauxella ferragutiae (type strain, ATCC 51602 [DSM 9390]), Buttiauxella gaviniae (type strain, ATCC 51604 [DSM 9393]), Buttiauxella brennerae (type strain, ATCC 51605 [DSM 9396]), Buttiauxella izardii (type strain, ATCC 51606 [DSM 9397]), Buttiauxella noackiae (type strain, ATCC 51607 [DSM 9401]), Buttiauxella warmboldiae (type strain, ATCC 51608 [DSM 9404]), Kluyvera cochleae (type strain, ATCC 51609 [DSM 9406]), and Kluyvera georgiana (type strain, ATCC 51603 [DSM 9409]).
\end{abstract}

In 1976, a taxon designated group $\mathrm{F}$ was described by Gavini et al. (15). The strains belonging to group F were originally isolated from humans, soil, and water in the course of a study on the genus Citrobacter, and they were lactose positive, as are members of the genus Citrobacter. However, these organisms differed from Citrobacter strains in several biochemical characteristics, as well as in their DNA-DNA-hybridization characteristics and guanine-plus-cytosine $(\mathrm{G}+\mathrm{C})$ ratios $(13,14)$. Hence, the 17 strains were considered members of a new genus in the family Enterobacteriaceae. This genus was named Buttiauxella and contained a single species Buttiauxella agrestis. Four strains subsequently studied by Ferragut et al. were placed in the genus Buttiauxella but were not B. agrestis strains (13). At the Centers for Disease Control and Prevention, three of these strains were placed in a group that was given the vernacular name enteric group 63 , and the fourth was placed in enteric group $64(10)$.

Also in the Centers for Disease Control and Prevention

\footnotetext{
* Corresponding author.

$\uparrow$ Present address: Institut für Angewandte Mikrobiologie, JustusLiebig Universität Giessen, D-35390 Giessen, Germany.
}

culture collection were more than 100 strains that were placed in a group designated enteric group 8. In 1981, Farmer et al. redefined the genus Kluyvera to include enteric group 8 along the named species Kluyvera ascorbata and Kluyvera cryocrescens and a third unnamed species (11). The genera Buttiauxella and Kluyvera are generally similar phenotypically, although they can be differentiated. The members of these genera have different $G+C$ contents and exhibit low levels of DNA relatedness (14).

The frequent and profuse occurrence of Buttiauxella and Kluyvera strains in snails and slugs is an intriguing finding. Numerous strains belonging to these previously rarely seen genera have been isolated. However, the phenotypic characteristics that separate these genera did not allow clear assignment of these isolates at the genus level. The biochemical reactions of the previously described species and the new isolates suggested that most of the new isolates belong to new species. In this paper we describe the results of a taxonomic study of Buttiauxella and Kluyvera strains.

\section{MATERIALS AND METHODS}

Bacterial strains. The Buttiauxella and Kluyvera strains used in this study are listed in Table 1. The field strains were isolated from snails and slugs and samples 
TABLE 1. Strains investigated in this study

\begin{tabular}{|c|c|c|c|c|c|}
\hline Group & $\begin{array}{c}\text { Serial } \\
\text { no. }\end{array}$ & Strain & $\begin{array}{l}\text { Labora- } \\
\text { tory(ies) }{ }^{a}\end{array}$ & Origin & Other designation $(\mathbf{s})^{b}$ \\
\hline DNA group 1 (B. agrestis) & $\begin{array}{l}001^{c} \\
002 \\
003 \\
004 \\
005 \\
006 \\
007 \\
008 \\
009 \\
010 \\
011 \\
012^{c} \\
013^{e} \\
014 \\
015 \\
016 \\
017^{e} \\
018^{e} \\
019 \\
020 \\
021^{e} \\
022^{e} \\
023^{e} \\
024^{e} \\
025^{e} \\
026^{e} \\
027 \\
028 \\
029^{e} \\
030^{e} \\
031^{e} \\
032^{e} \\
033^{e} \\
034 \\
035 \\
036 \\
037^{e} \\
038 \\
039 \\
040 \\
041 \\
042^{e} \\
043 \\
044 \\
045 \\
046 \\
047 \\
048 \\
049 \\
050 \\
051 \\
052 \\
053^{e}\end{array}$ & $\begin{array}{l}\text { CDC } 1176-81^{\mathrm{T}}\left(=\text { CUETM } 77-167^{\mathrm{T}}\right) \\
\text { CUETM } 77-157 \\
\text { CUETM } 78-3 \\
\text { CUETM 78-5 } \\
\text { CUETM 78-8 } \\
\text { CUETM } 78-18 \\
\text { CUETM } 78-19 \\
\text { CUETM } 78-27 \\
\text { CUETM } 78-29 \\
\text { CUETM } 78-34 \\
\text { CUETM } 78-44 \\
\text { S3/3-162 } \\
\text { S3/3-203 } \\
\text { S3/4-204 } \\
\text { S3/4-556 } \\
\text { S3/4-775 } \\
\text { S3/4-776 } \\
\text { S3/4-779 } \\
\text { S3/4-871 } \\
\text { S3/4-1098 } \\
\text { S3/5-201 } \\
\text { S3/5-757 } \\
\text { S3/6-333 } \\
\text { S3/7-896 } \\
\text { S3/7-897 } \\
\text { S3/8-910 } \\
\text { S3/9-488 } \\
\text { S3/9-602 } \\
\text { S3/9-878 } \\
\text { S3/9-887 } \\
\text { S3/10-769 } \\
\text { S3/11-533 } \\
\text { S3/11-794 } \\
\text { S3/11-832 } \\
\text { S3/11-859 } \\
\text { S3/14-770 } \\
\text { S3/14-1071 } \\
\text { S3/14-1073 } \\
\text { S3/14-1080 } \\
\text { S3/14-1081 } \\
\text { S3/14-1082 } \\
\text { S3/14-1085 } \\
\text { S3/14-1094 } \\
\text { S3/14-1096 } \\
\text { S3/14-1099 } \\
\text { S3/14-1101 } \\
\text { S3/14-1127 } \\
\text { S3/14-1129 } \\
\text { S3/14-1132 } \\
\text { S3/14-1146 } \\
\text { S3/14-1149 } \\
\text { S3/14-1166 } \\
\text { S3/13-692 }\end{array}$ & $\begin{array}{l}1,4 \\
4 \\
4 \\
4 \\
4 \\
4 \\
4 \\
4 \\
4 \\
4 \\
4 \\
3 \\
3 \\
3 \\
3 \\
3 \\
3 \\
3 \\
3 \\
3 \\
3 \\
3 \\
3 \\
3 \\
3 \\
3 \\
3 \\
3 \\
3 \\
3 \\
3 \\
3 \\
3 \\
3 \\
3 \\
3 \\
3 \\
3 \\
3 \\
3 \\
3 \\
3 \\
3 \\
3 \\
3 \\
3 \\
3 \\
3 \\
3 \\
3 \\
3 \\
3 \\
3\end{array}$ & $\begin{array}{l}\text { Unpolluted soil, France }{ }^{d} \\
\text { Drinking water, France } \\
\text { Unpolluted soil, France }^{d} \\
\text { Unpolluted soil, France }^{d} \\
\text { Drinking water, France } \\
\text { Unpolluted soil, France }^{d} \\
\text { Drinking water, France } \\
\text { Drinking water, France }^{d} \\
\text { Drinking water, France } \\
\text { Unpolluted soil, France }^{d} \\
\text { Drinking water, France } \\
\text { Snail, Braunschweig, Germany } \\
\text { Snail, Braunschweig, Germany } \\
\text { Snail, Braunschweig, Germany } \\
\text { Snail, Braunschweig, Germany } \\
\text { Snail, Braunschweig, Germany } \\
\text { Snail, Braunschweig, Germany } \\
\text { Snail, Braunschweig, Germany } \\
\text { Snail, Braunschweig, Germany } \\
\text { Slug, Braunschweig, Germany } \\
\text { Snail, Braunschweig, Germany } \\
\text { Snail, Braunschweig, Germany } \\
\text { Slug, Braunschweig, Germany } \\
\text { Slug, Braunschweig, Germany } \\
\text { Snail, Braunschweig, Germany } \\
\text { Slug, Salisbury, Great Britain } \\
\text { Slug, Braunschweig, Germany } \\
\text { Snail, Braunschweig, Germany } \\
\text { Snail, Braunschweig, Germany } \\
\text { Slug, Braunschweig, Germany } \\
\text { Snail, Braunschweig, Germany } \\
\text { Slug, Braunschweig, Germany } \\
\text { Snail, Braunschweig, Germany } \\
\text { Snail, Braunschweig, Germany } \\
\text { Snail, Braunschweig, Germany } \\
\text { Snail, Braunschweig, Germany } \\
\text { Slug, Braunschweig, Germany } \\
\text { Slug, Braunschweig, Germany } \\
\text { Slug, Braunschweig, Germany } \\
\text { Slug, Braunschweig, Germany } \\
\text { Slug, Braunschweig, Germany } \\
\text { Slug, Braunschweig, Germany } \\
\text { Slug, Braunschweig, Germany } \\
\text { Slug, Braunschweig, Germany } \\
\text { Slug, Braunschweig, Germany } \\
\text { Slug, Braunschweig, Germany } \\
\text { Slug, Braunschweig, Germany } \\
\text { Slug, Braunschweig, Germany } \\
\text { Slug, Braunschweig, Germany } \\
\text { Slug, Braunschweig, Germany } \\
\text { Slug, Braunschweig, Germany } \\
\text { Slug, Braunschweig, Germany } \\
\text { Slug, Braunschweig, Germany }\end{array}$ & $\begin{array}{l}\text { ACTT } 33994 \\
\text { ATCC } 33995\end{array}$ \\
\hline $\begin{array}{l}\text { DNA group } 2 \text { (enteric } \\
\text { group } 63, B \text {. ferragutiae) }\end{array}$ & $\begin{array}{l}054^{c} \\
055 \\
056 \\
057\end{array}$ & $\begin{array}{l}\text { CDC } 1180-81^{\mathrm{T}}\left(=\text { CUETM } 78-31^{\mathrm{T}}\right) \\
\text { CUETM } 78-50 \\
\text { CUETM } 78-35 \\
\text { CUETM "H. alvei } 125 \text { " }\end{array}$ & $\begin{array}{l}1,4 \\
4 \\
4 \\
4\end{array}$ & $\begin{array}{l}\text { Unpolluted soil, France (13) } \\
\text { Drinking water, France (13) } \\
\text { Unpolluted soil, France (13) } \\
\text { Unknown, France }\end{array}$ & $\begin{array}{l}\text { ATCC } 51602^{\mathrm{T}} \text {, DSM } 9390^{\mathrm{T}} \\
\text { DSM } 9391\end{array}$ \\
\hline $\begin{array}{l}\text { DNA group } 3 \text { (enteric } \\
\text { group 64, B. gaviniae) }\end{array}$ & $\begin{array}{l}058^{c} \\
059 \\
060 \\
061 \\
062^{c} \\
063^{e} \\
064 \\
065 \\
066\end{array}$ & $\begin{array}{l}\text { CDC 1175-81 (= CUETM 77-159) } \\
\text { S1/1-895 } \\
\text { S1/1-978 } \\
\text { S1/1-981 } \\
\text { S1/1-984 } \\
\text { S1/1-986 } \\
\text { S1/1-987 } \\
\text { S1/1-988 } \\
\text { S1/1-993 }\end{array}$ & $\begin{array}{l}1,4 \\
3 \\
3 \\
3 \\
3 \\
3 \\
3 \\
3 \\
3\end{array}$ & $\begin{array}{l}\text { Unpolluted soil, France (13) } \\
\text { Slug, Braunschweig, Germany } \\
\text { Snail, Braunschweig, Germany } \\
\text { Snail, Braunschweig, Germany } \\
\text { Snail, Braunschweig, Germany } \\
\text { Snail, Braunschweig, Germany } \\
\text { Snail, Braunschweig, Germany } \\
\text { Snail, Braunschweig, Germany } \\
\text { Snail, Braunschweig, Germany }\end{array}$ & ATCC 51604, DSM 9393 \\
\hline
\end{tabular}


TABLE 1-Continued

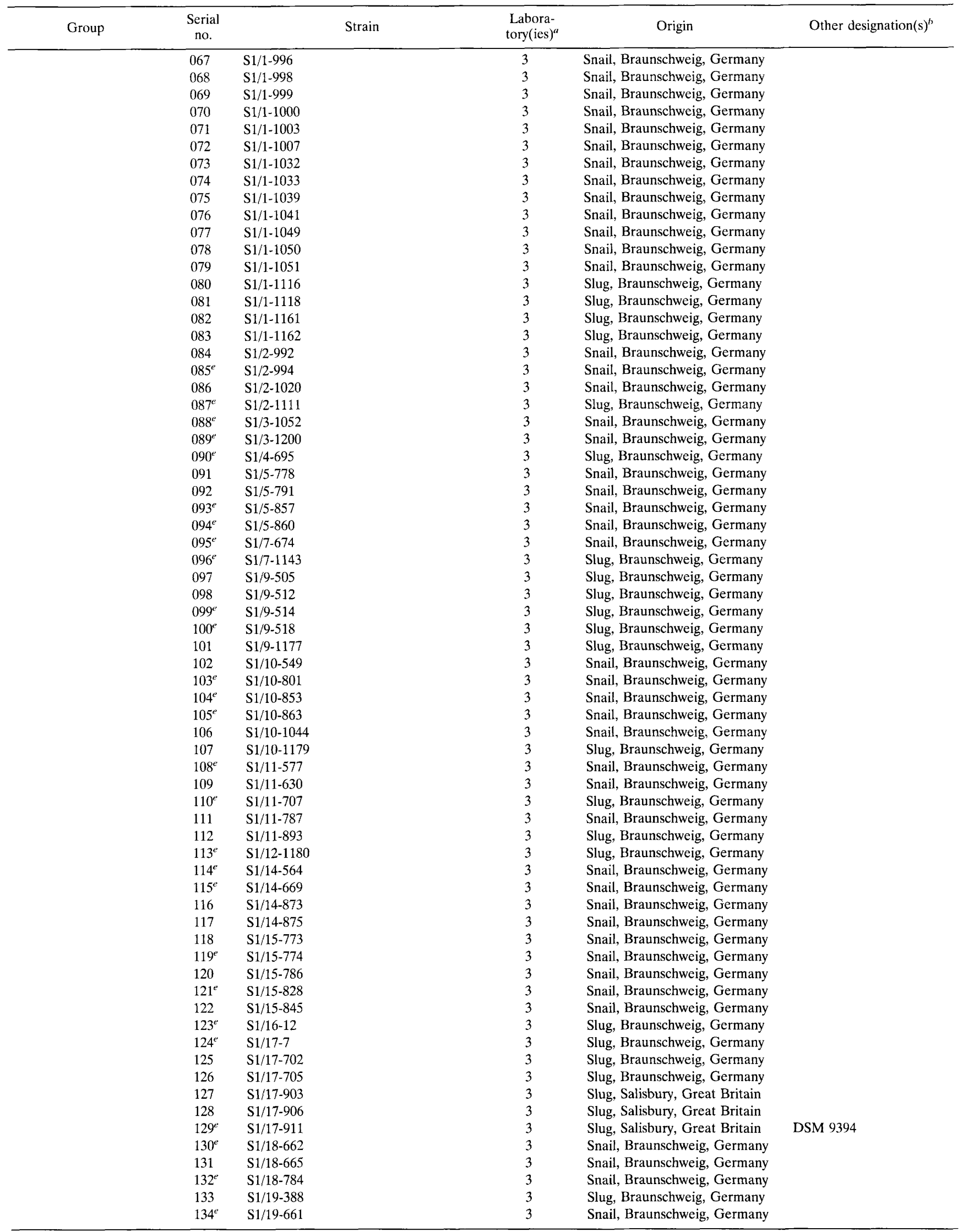


TABLE 1-Continued

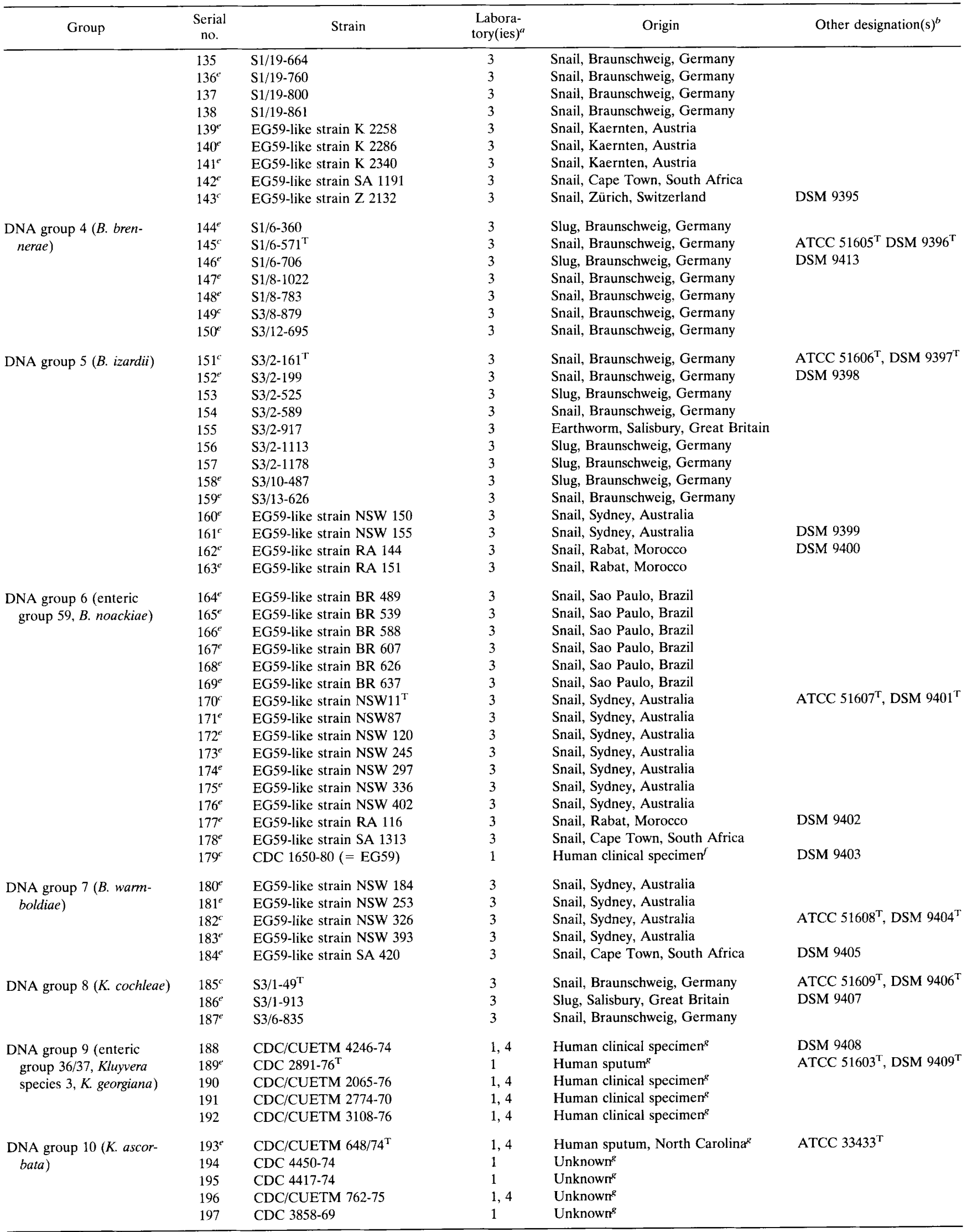


TABLE 1 -Continued

\begin{tabular}{|c|c|c|c|c|c|}
\hline Group & $\begin{array}{l}\text { Serial } \\
\text { no. }\end{array}$ & Strain & $\begin{array}{l}\text { Labora- } \\
\text { tory(ies) }{ }^{a}\end{array}$ & Origin & Other designation $(\mathrm{s})^{b}$ \\
\hline \multirow{19}{*}{$\begin{array}{l}\text { DNA group } 11 \text { ( } K \text { cryo- } \\
\text { crescens) }\end{array}$} & 198 & CDC $1220-73$ & 1 & Unknown ${ }^{g}$ & \\
\hline & 199 & CDC $972-78$ & 1 & Unknown ${ }^{g}$ & \\
\hline & 200 & CDC $2070-78$ & 1 & Unknown ${ }^{g}$ & \\
\hline & 201 & CUETM 1-79 & 4 & Unknown & \\
\hline & 202 & CDC 2064-78 & 1 & Unknown ${ }^{g}$ & \\
\hline & 203 & CDC $2589-70$ & 1 & Unknown ${ }^{g}$ & \\
\hline & 205 & CDC 2221-78 & 1 & Human (?), New York ${ }^{g}$ & ATCC 33434 \\
\hline & 206 & CUETM $9-79$ & 4 & Unknown & \\
\hline & 207 & CUETM 20-74 & 4 & Unknown & \\
\hline & 208 & CUETM 14-79 & 4 & Unknown & \\
\hline & 209 & CUETM 3-79 & 4 & Unknown & \\
\hline & 210 & CDC/CUETM 1734-74 & 1,4 & Unknown ${ }^{g}$ & \\
\hline & 211 & CDC/CUETM 1396-73 & 1,4 & Unknown ${ }^{g}$ & \\
\hline & $214^{e}$ & CDC $2065-78^{\mathrm{T}}$ & 1 & Kitchen food, Persian Gulf $f^{g}$ & $\operatorname{ATCC} 33435^{\mathrm{T}}$ \\
\hline & 215 & CDC 2568-61 & 1 & Unknown & ATCC 14237 \\
\hline & 216 & CDC 2569-61 & 1 & Unknown & ATCC 14238 \\
\hline & 217 & BU 00512810484 & 2 & Unknown & DSM 9410 \\
\hline & 218 & BU 00933728683 & 2 & Unknown & DSM 9411 \\
\hline & 219 & BU $01014812 \mathrm{~T}$ & 2 & Unknown & DSM 9412 \\
\hline
\end{tabular}

"1, Centers for Disease Control and Prevention, Atlanta, Ga., 2, Fachgebiet Hygiene, Technische Universität, Berlin, Germany; 3, Staatliches Medizinaluntersuchungsamt, Braunschweig, Germany; 4, Institut Pasteur, Paris, France.

${ }^{b}$ ATCC, American Type Culture Collection; DSM, Deutsche Sammlung von Mikroorganismen und Zellkulturen.

c P-labeled strain.

"See reference 13

${ }^{e}$ Strain used in DNA-DNA hybridization experiments.

' $\mathrm{S}$ See reference 10

${ }^{g}$ See reference 11

were obtained from around the world. The strains were identified in two steps. The first step involved screening tests to identify organisms that were members of the family Enterobacteriaceae (rod-shaped, gram-negative, oxidase-negative, catalase-positive organisms that fermented D-glucose, reduced nitrate, and exhibited unusual L-arginine dihydrolase, L-lysine decarboxylase, and L-ornithine decarboxylase activity patterns [i.e., strains that were L-arginine dihydrolase negative, $\mathrm{L}$-lysine decarboxylase negative, and L-ornithine decarboxylase positive, strains that were L-arginine decarboxylase positive, L-lysine decarboxylase negative, and L-ornithine decarboxylase negative, and strains that were L-arginine decarboxylase positive, L-lysine decarboxylase negative, and L-ornithine decarboxylase positive]). After this step additional tests (Table 2) were performed.

DNA relatedness. DNA-DNA hybridization experiments were performed with 95 strains. To obtain DNA, cells were grown in brain heart infusion broth at 36 $\pm 1^{\circ} \mathrm{C}$ with shaking until they reached the late logarithmic phase. The methods used to extract and purify DNA and the batch hydroxyapatite method used for DNA-DNA hybridization have been described previously (6). An incubation temperature of $60^{\circ} \mathrm{C}$ was used for optimal DNA reassociation, and an incubation temperature of $75^{\circ} \mathrm{C}$ was used for stringent DNA reassociation. Labeled DNAs from strains $001,012,054,058,062,143,145,149,151,161,170,179,182$, and 185 (serial numbers [Table 1]) were prepared enzymatically in vitro with $\left[{ }^{32} \mathrm{P}\right] \mathrm{dCTP}$ by using a nick translation reagent kit (Gibco BRL, Gaithersburg, Md.) as directed by the manufacturer. Levels of relatedness were expressed as relative binding ratios, and the level of divergence of related sequences was determined by calculating the decrease in thermal stability in a heteroduplex (reassociated labeled and unlabeled DNAs from two different strains) compared with the thermal stability in a homoduplex (reassociated labeled and unlabeled DNAs from the same strain). Levels of divergence were calculated to the nearest $0.5 \%$ on the assumption that each $1^{\circ} \mathrm{C}$ decrease in heteroduplex DNA stability was due to approximately $1 \%$ unpaired (diverged) bases within the related DNA $(3,4,11$, 16). A species was defined as a group of strains that exhibited levels of DNA relatedness at the optimal reassociation temperature of $70 \%$ or more and whose related sequences exhibited $5 \%$ or less divergence (19).

Biochemical tests. Routine biochemical tests were performed by using standardized procedures, and results were recorded after $48 \mathrm{~h}$ of incubation at 30 $1^{\circ} \mathrm{C}(8,9,12)$. Consistent results for the decarboxylase reactions were obtained by using the medium of Fay and Barry at pH 5.5 (1). Carbon source utilization tests were performed at the Institut Pasteur Paris by using Biotype strips (bioMérieux, La Balme les Grottes, France) that contained 99 pure carbon sources. The strips were inoculated by using Biotype medium 1 as recommended by the manufacturer. The strips were incubated at $30^{\circ} \mathrm{C}$ for 4 days, and growth was assessed visually daily. In the esculin, hydroxyquinoline, $\beta$-glucuronide, tryptophan, and histidine tests development of a color (black, orange to brown, and dark red, respectively) was considered a positive reaction (5). At the Technische Universität Berlin carbon source utilization tests were performed in microtiter plates (flat-bottom wells) by using filter-sterilized M70 minimal medium (18) supplemented with $0.002 \%$ (wt/vol) yeast extract (Oxoid) and $0.002 \%(\mathrm{wt} / \mathrm{vol}$ ) bio-Lactysat (bio-Mérieux). Each filter-sterilized carbon source was added at a final concentration of $0.2 \%(\mathrm{wt} / \mathrm{vol})$. For aromatic compounds, a concentration of $0.05 \%$ (wt/vol) was used. Qualitative enzyme tests were performed in filter sterilized media ( $\mathrm{pH} 7.2$ ) containing $0.05 \mathrm{M}$ Tris $\mathrm{HCl}$ buffer, $0.05 \%$ yeast extract (Oxoid), and $0.05 \%$ bio-Lactysat (bio-Mèrieux). Filter-sterilized solutions of chromogenic substrates ( $p$-nitrophenyl-linked compounds) were added at a final concentration of $2 \mathrm{mM}$. For $p$-nitroanilides, a concentration of $1 \mathrm{mM}$ was used The preparations were incubated at $30^{\circ} \mathrm{C}$, and growth was assessed visually daily for 4 days by comparing the cultures with a control that did not contain substrate.

Calculation of phenotypic probability distances. The probability distance (pd) for each pair of species was calculated in two steps by the using average percentages ( $\mathrm{v} 1$ and $\mathrm{v} 2$ ) obtained from discriminating tests ( $\mathrm{t} 1$ to $\mathrm{tn}$ ). First, the larger of the two average percentages for two taxa was divided by the smaller, giving a value of $>1\left(\mathrm{v} 2 / \mathrm{v} 1_{\mathrm{t}}\right)$. Because this calculation failed for values of 0 and $100 \%$, these values were replaced by 0.001 and $99,99 \%$, respectively, without any practical disadvantage. Thereafter, $n$ quotients of $n$ tests were multiplied (pd $=$ $\left.\mathrm{v} 2 / \mathrm{v} 1_{\mathrm{t} 1} \times \mathrm{v} 2 / \mathrm{v} 1_{\mathrm{t} 2} \cdots \times \cdots \cdot \mathrm{v} 2 / \mathrm{v} 1_{\mathrm{tn}}\right)$. Low values represented close probability distances and high levels of phenotypic relatedness and vice versa (Tables 3 through 5).

\section{RESULTS AND DISCUSSION}

Habitat. The few previously described Buttiauxella strains were isolated from unpolluted soil and drinking water, surface water, sewage, soil, and fecal samples, and to our knowledge no Buttiauxella strains have been isolated from primary sterile clinical specimens. Kluyvera strains have been isolated more frequently than Buttiauxella strains but often appear to be biochemically different from members of the previously described species, $K$ ascorbata and $K$. cryocrescens $(2,7,17)$. Kluyvera strains have been isolated from both soil and clinical 


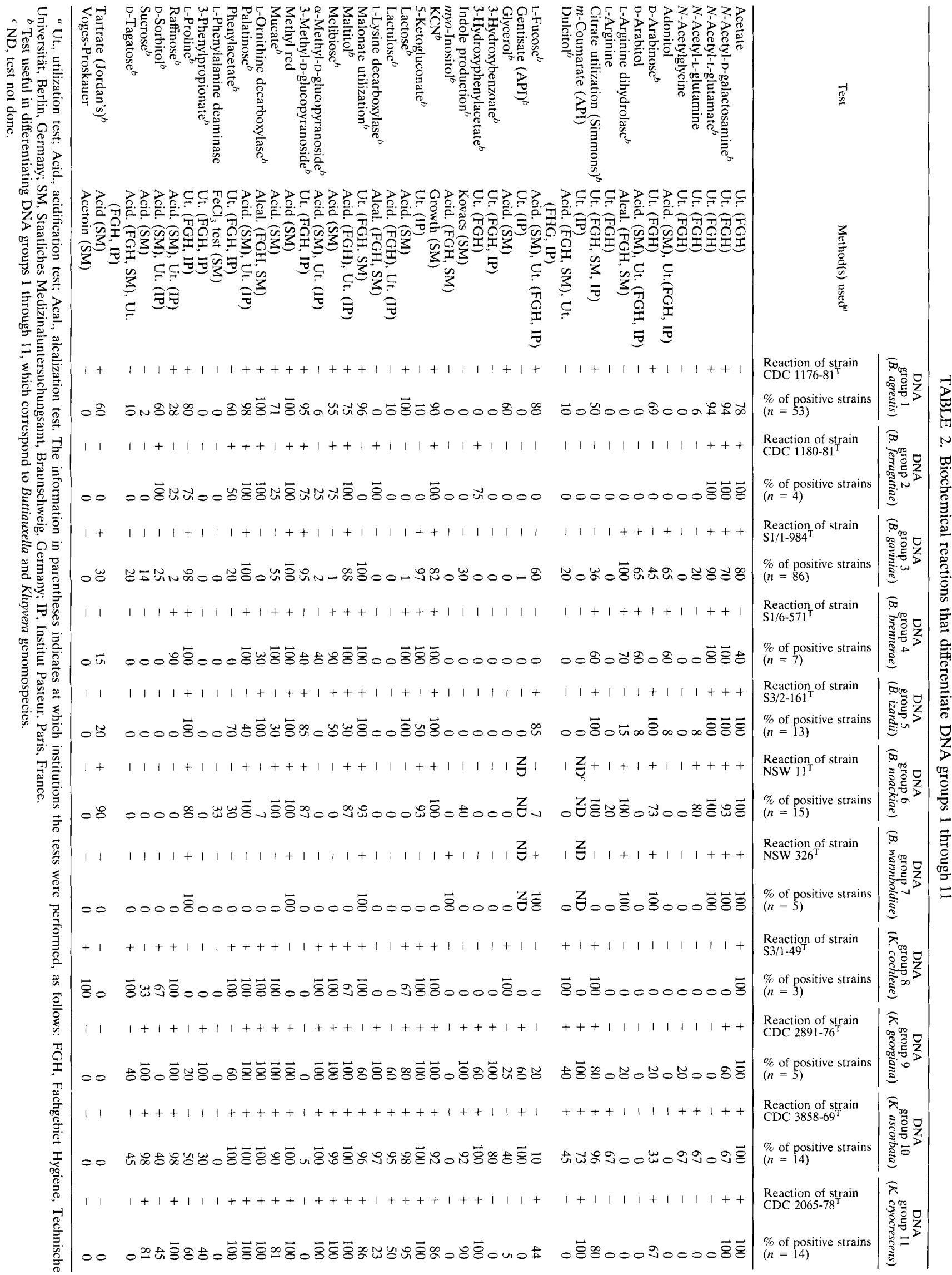


TABLE 3. Logarithms of probability distances and relative binding ratios

\begin{tabular}{|c|c|c|c|c|c|c|c|c|c|c|}
\hline \multirow{2}{*}{$\begin{array}{l}\text { DNA } \\
\text { group }\end{array}$} & \multicolumn{10}{|c|}{ Logarithm of probability distances or relative binding ratio at $60^{\circ} \mathrm{C}^{a}$} \\
\hline & $\begin{array}{l}\text { DNA } \\
\text { group } 1\end{array}$ & $\begin{array}{c}\text { DNA } \\
\text { group } 2\end{array}$ & $\begin{array}{c}\text { DNA } \\
\text { group } 3\end{array}$ & $\begin{array}{c}\text { DNA } \\
\text { group } 4\end{array}$ & $\begin{array}{c}\text { DNA } \\
\text { group } 5\end{array}$ & $\begin{array}{c}\text { DNA } \\
\text { group } 6\end{array}$ & $\begin{array}{l}\text { DNA } \\
\text { group } 7\end{array}$ & $\begin{array}{c}\text { DNA } \\
\text { group } 8\end{array}$ & $\begin{array}{c}\text { DNA } \\
\text { group } 9\end{array}$ & $\begin{array}{c}\text { DNA } \\
\text { group 10 }\end{array}$ \\
\hline 1 & & 50.60 & 55.64 & 53.33 & 62.67 & 58.00 & 56.00 & & & \\
\hline 2 & 23.92 & & 50.2 & 49.83 & 48.33 & 55.00 & 49.00 & & & \\
\hline 3 & 22.28 & 34.50 & & 60.16 & 52.40 & 70.50 & 48.71 & & & \\
\hline 4 & 23.42 & 24.65 & 23.05 & & 52.56 & 55.00 & 49.25 & & & \\
\hline 5 & 15.46 & 26.94 & 19.44 & 16.21 & & 50.29 & 48.00 & & & \\
\hline 6 & 24.77 & 31.60 & 16.77 & 24.31 & 16.93 & & 47.92 & & & \\
\hline 7 & 35.99 & 33.59 & 30.89 & 33.61 & 26.60 & 27.86 & & & & \\
\hline 8 & 26.65 & 33.47 & 40.15 & 31.43 & 36.52 & 43.76 & 50.90 & & & \\
\hline 9 & 30.57 & 35.89 & 39.04 & 35.43 & 36.22 & 40.66 & 50.19 & 28.28 & & \\
\hline 10 & 28.82 & 36.41 & 39.83 & 41.42 & 39.95 & 40.01 & 57.77 & 29.73 & 10.79 & \\
\hline 11 & 23.16 & 26.39 & 35.26 & 30.47 & 28.97 & 34.86 & 43.35 & 26.32 & 13.77 & 14.88 \\
\hline
\end{tabular}

"The values on the lower left are logarithms of phenotypic probability distances; these values were calculated by using all of the data in Table 2 except the $m$ coumarate and gentisate data. The values on the upper right are relative binding ratios at $60^{\circ} \mathrm{C}$ (expressed as percentages); these values were obtained from Table 6 .

sources, although soil, water, and humans do not seem to be the normal habitats of Kluyvera species $(14,15)$.

Our experience indicates that strains of both genera occur frequently and abundantly in the intestines of snails, slugs, and other mollusks. The apparent diversity of the different Buttiauxella and Kluyvera species isolated from mollusks is an additional reason to consider these animals to be the ecologic niche and natural source of these bacteria.

DNA relatedness. The results of our DNA-DNA relatedness experiments revealed that there were 11 DNA hybridization groups or genomospecies (Table 6). Eighteen snail and slug isolates and the type strain of $B$. agrestis were in hybridization group 1. None of the mollusk isolates were in hybridization group 2, which corresponds to the unnamed Buttiauxella species called enteric group 63; this was due to the screening tests used during isolation. The strains isolated were distinguished on the basis of a negative lysine decarboxylase test. Since enteric group 63 strains are positive for this reaction, if they were present, they would have been eliminated by the screening procedure used. Hybridization group 3, represented by enteric group 64 containing one previously described strain, contained 35 snail and slug strains. Hybridization groups 4, 5 , and 7 each represented previously unrecognized species containing seven, nine, and five strains, respectively. Hybridization group 6, represented by the unnamed species enteric group 59 , contained 15 snail and slug strains.

None of the Kluyvera-like strains hybridized at the species level to members of hybridization group 10 ( $K$. ascorbata), hybridization group 11 (K. cryocrescens), or hybridization group 9 (unnamed Kluyvera species 3 [11, 14]). Three Kluyvera-like strains isolated from snails and slugs belonged to hybridization group 8. Essentially without exception, the levels of relatedness within each hybridization group were more than $70 \%$ at both the optimal temperature $\left(60^{\circ} \mathrm{C}\right)$ and the stringent temperature $\left(75^{\circ} \mathrm{C}\right)$ used for DNA reassociation (Table 6). Similarly, essentially without exception, the levels of divergence within related sequences were $5 \%$ or less. These levels of relatedness correspond to the levels recommended for strains belonging to a single species (19).

The levels of relatedness obtained for members of hybridization groups 1 through 7 were generally between 45 and $65 \%$, a good indication that all of these groups belong to a single genus, the genus Buttiauxella. The hybridization groups that exhibited the highest levels of relatedness were hybridization groups 1 and 5 and hybridization groups 3 and 6 . The members of hybridization group 8 were 44 to $48 \%$ related to the type strains of the two previously described and one previously unnamed Kluyvera species, but only 13 to $25 \%$ related to the

TABLE 4. Results obtained when DNA groups were compared

\begin{tabular}{|c|c|c|c|}
\hline Comparison & $\begin{array}{l}\text { No. of } \\
\text { tests }\end{array}$ & $\begin{array}{l}\text { Phenotypic probability distance } \\
\text { (mean } \pm \mathrm{SD})\end{array}$ & $\begin{array}{l}\text { DNA-DNA relatedness value } \\
\quad(\text { mean } \pm \mathrm{SD})\end{array}$ \\
\hline Within the genus Buttiauxella & 21 & $25.37 \pm 6.31$ & $53.49 \pm 5.69$ \\
\hline DNA group 1 vs DNA groups 2 through 7 & 6 & $24.31 \pm 6.63$ & $56.04 \pm 4.12$ \\
\hline DNA group 2 vs DNA groups 1 and 3 through 7 & 6 & $29.20 \pm 4.62$ & $50.49 \pm 2.36$ \\
\hline DNA group 3 vs DNA groups 1,2, and 4 through 7 & 6 & $24.49 \pm 6.83$ & $56.27 \pm 8.09$ \\
\hline DNA group 4 vs DNA groups 1 through 3 and 5 through 7 & 6 & $24.21 \pm 5.56$ & $53.36 \pm 3.97$ \\
\hline DNA group 5 vs DNA groups 1 through 4 , and 7 & 6 & $20.26 \pm 5.22$ & $52.38 \pm 5.40$ \\
\hline DNA group 7 vs DNA groups 1 through 6 & 6 & $31.42 \pm 3.65$ & $49.81 \pm 3.08$ \\
\hline Buttiauxella DNA groups vs Kluyvera DNA groups & 28 & $37.06 \pm 7.79$ & \\
\hline Within the genus Kluyvera & 6 & $20.63 \pm 8.37$ & \\
\hline DNA group 8 vs DNA groups 9 through 11 & 3 & $26.55 \pm 2.55$ & \\
\hline DNA group 9 vs DNA groups 8,10 , and 11 & 3 & $17.61 \pm 9.36$ & \\
\hline DNA group 10 vs DNA groups 8,9 , and 11 & 3 & $18.47 \pm 9.97$ & \\
\hline
\end{tabular}




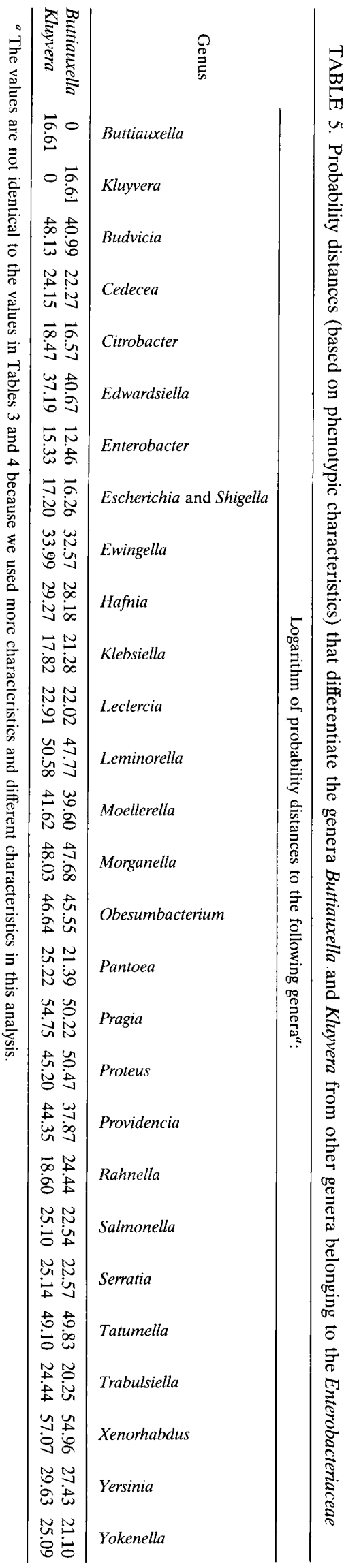

members of the seven Buttiauxella hybridization groups, which is consistent with placement of hybridization group 8 in the genus Kluyvera. The levels of relatedness between members of the Buttiauxella and Kluyvera hybridization groups and more than 50 other species belonging to the Enterobacteriaceae were generally between 15 and $30 \%$ (data not shown).

Certain strains included in the hybridization groups exhibited higher levels of divergence (more than $5 \%$ ) or lower levels of relatedness (less than $70 \%$ in $60^{\circ} \mathrm{C}$ reactions or less than $60 \%$ in $75^{\circ} \mathrm{C}$ reactions) than the levels used in the definition of a genetic species (19). In almost all cases, these borderline strains deviated in only one of the three parameters used to determine species level relatedness, and their levels of relatedness with a second reference strain were fully within the species definition. For example, EG59-like strain NSW 155 in hybridization group 4 was $66 \%$ related to the reference strain at $60^{\circ} \mathrm{C}$ but exhibited only $0.5 \%$ divergence and the level of relatedness at $75^{\circ} \mathrm{C}$ was $66 \%$. Similarly, strain S1/3-1052 in hybridization group 3 exhibited $5.5 \%$ divergence with one reference strain, but $5.0 \%$ divergence with the second reference strain, and, in both cases the levels of relatedness at both temperatures were well within the limits used to define species. In every case, all of the strains belonging to a relatedness group exhibited similar biochemical reactions. Therefore, we decided that they should be included in the relatedness group, at least for the present.

Phenotypic and chemotaxonomic characterization. All of the strains studied were gram-negative, oxidase-negative, catalasepositive, D-glucose-fermenting, nitrate-reducing, rod-shaped organisms belonging to the family Enterobacteriaceae. They grew on MacConkey agar and on Endo agar at $30^{\circ} \mathrm{C}$. With few exceptions, all of the strains were positive in standard tests for motility, acid and gas production from D-glucose, fermentation of D-mannitol, salicin, L-arabinose, L-rhamnose, maltose, Dxylose, trehalose, cellobiose, D-mannose, galactose, gentiobiose, $\mathrm{D}$-ribose, and arbutin, esculin hydrolysis, and $o$-nitrophenyl- $\beta$ $D$-galactopyranoside ( $\beta$-galactosidase) test. They were negative for production of hydrogen sulfide on triple sugar iron, Christensen urease activity, gelatin liquefaction, lipase activity (Tween 80 and corn oil), DNase activity, and production of a yellow pigment or some other pigment and did not ferment 2-deoxy-D-glucose, 2-deoxy-D-ribose, erythritol, $\alpha$-D-fucose, Dlyxose, and xylitol.

Almost all of the strains utilized the following compounds as sole carbon and energy sources: $N$-acetyl-D-glucosamine, Dalanine, L-alanine, L-arabinose, arbutin, DL-asparagine, D-cellobiose, $\mathrm{D}$-fructose, D-galactose, D-galacturonate, gentiobiose, D-gluconate, D-glucosamine, D-glucuronate, L-glutamine, L-glutamate, DL-glycerate, glycerol, 4-hydroxybenzoate, 2-ketogluconate, D-lactate, DL-lactate, maltose, maltotriose, mannitol, $D$-mannose, methyl- $\alpha$-galactoside, methyl- $\beta$-galactoside, methyl- $\beta$-D-glucoside, mucate, oxaloacetate, palatinose, protocatechuate, pyruvate, quinate, L-rhamnose, D-ribose, D-saccharate, salicin, L-serine, starch, D-trehalose, and D-xylose.

Almost all of the strains were not able to utilize the following compounds as sole carbon and energy sources: acetamide, acetamidocaprate, $N$-acetyl-DL-methionine, $N$-acetyl-L-proline, cis-aconitate, trans-aconitate, adipate, $\beta$-alanine, allantoin, altrose, DL-2-aminoadipate, 2-aminobenzoate, 3-aminobenzoate, 4-aminobenzoate, DL-2-aminobutyrate, DL-3-aminobutyrate, 4aminobutyrate, DL-2-amino-isobutyrate, DL-3-amino-isobutyrate, 5-aminovalerate, aminoxyacetate, amygdalin, anthranilate, 2-hydroxy-phenylacetate, L-arabitol, arabonate, D-arginine, Dasparagine, azelate, benzoate, betaine, 1-butanol, 2-butanol, $n$-butyrate, isobutyrate, cadaverine, caprate, caprylate, carnitine, carnosine, L-citrulline, citraconate, L-cysteinate, dextran, 


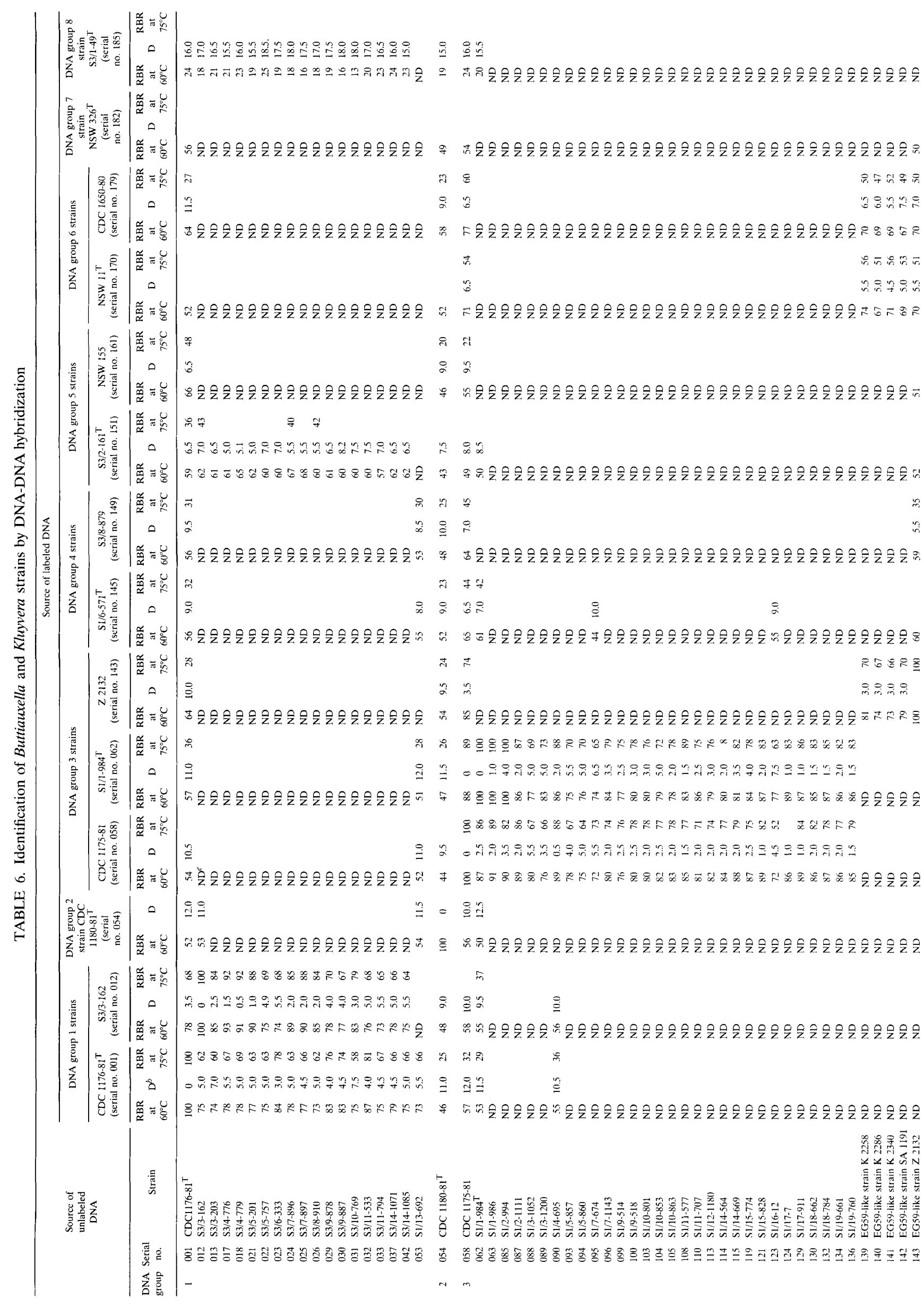




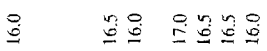

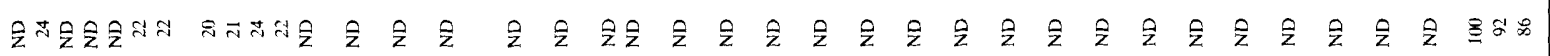
\% $\&$ \& 8

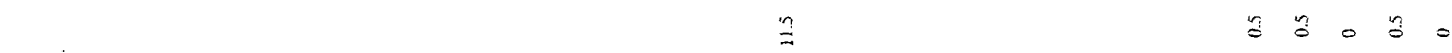

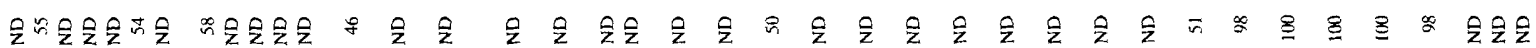

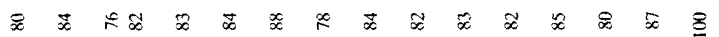

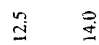

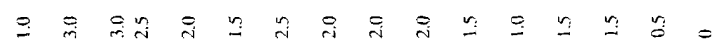

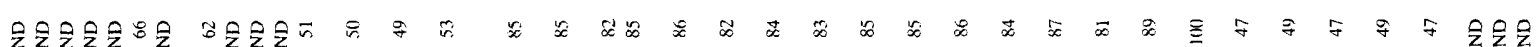

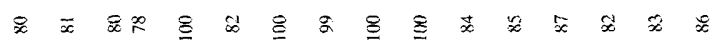

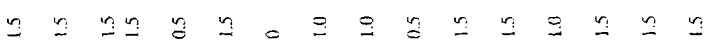

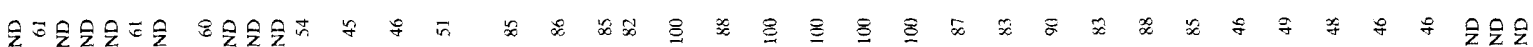

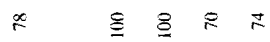
$\therefore \quad s \circ \bar{i}$

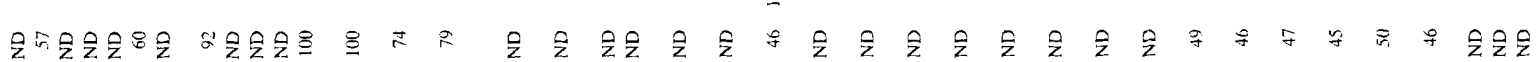

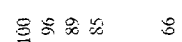

क

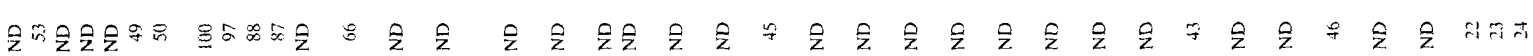

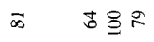

$\therefore \quad \dot{s i n}_{0}=$

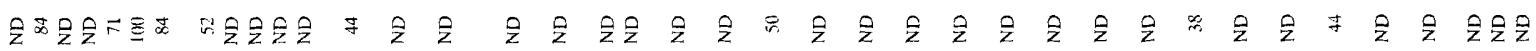

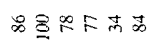

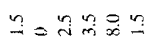

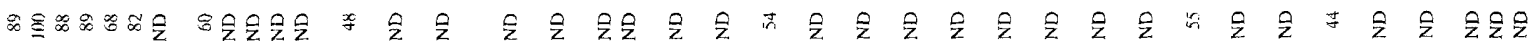
$\rightarrow n$

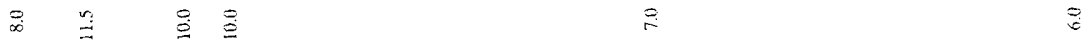

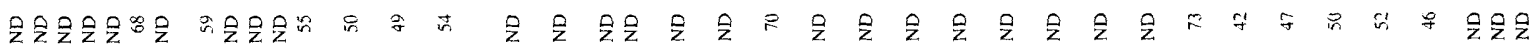
乎表名尔学

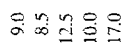

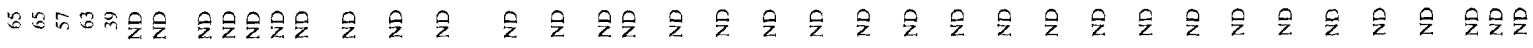

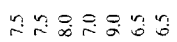

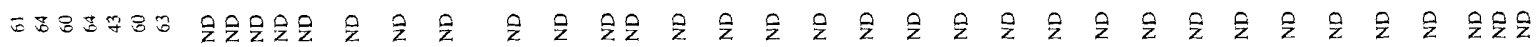

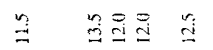

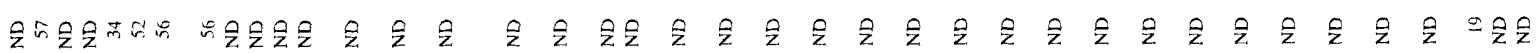
m

a. $\stackrel{a}{\exists}$

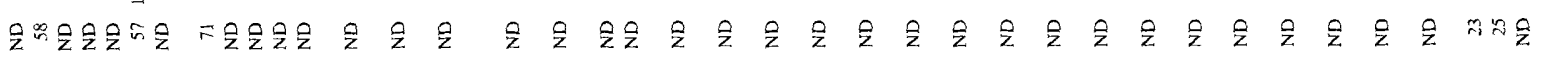

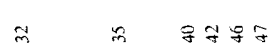

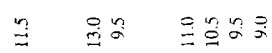

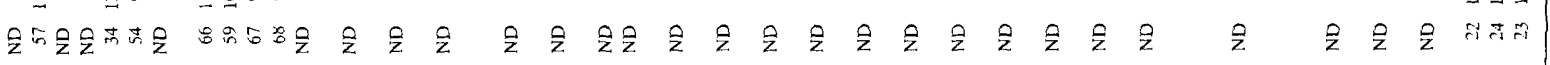

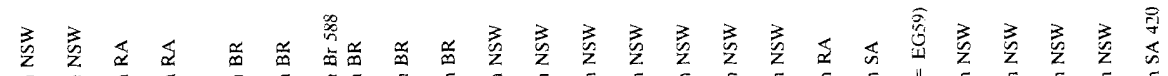

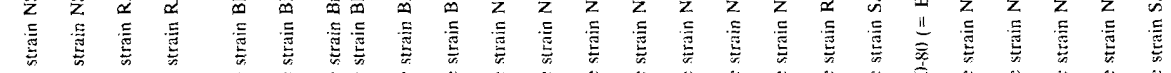

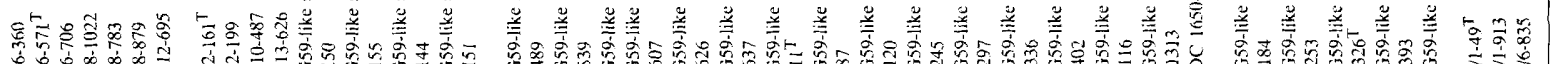

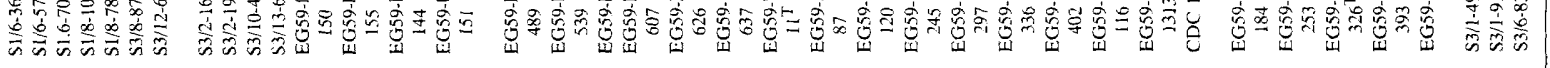

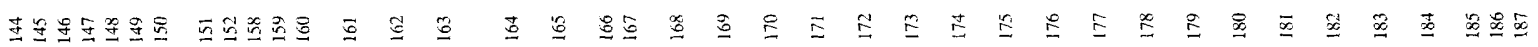


DL-2,4-diaminobutyrate, diaminopimelate, 2,3-diaminopropionate, dimethylglycine, $m$-erythritol, ethanol, ethanolamine, ethylamine, D-fucose, D-glutamate, glutarate, glycinamide, glycogen, glycolate, glycyrrhizinate, 1-hexanol, 1,6-hexandiol, hexylamine, hippurate, histamine, D-histidine, L-histidine, Lhomoserine, DL-3-hydroxybutyrate, 4-hydroxybutyrate, DL-2-hydroxycaprate, DL-2-hydroxy-isobutyrate, L-2-hydroxyisocaprate, 2-hydroxy-isovalerate, DL- $\gamma$-hydroxylysine, 4-hydroxyphenylglycine, DL-hydroxyproline, 2-hydroxyvalerate, HQ- $\beta$-glucuronide, heptanoate, indole-3-acetate, isophthalate, itaconate, 2-ketoglutarate, 2-ketoisocaprate, D-leucine, L-leucine, levulinate, D-lysine, D-malate, maleate, D-mandelate, L-mandelate, $\mathrm{D}$-mannoheptulose, D-melezitose, mesaconate, mesoxalate, D-methionine, L-methionine, DL-methioninesulfone, methyl- $\alpha$ D-glucoside, $\alpha$-methyl-D-mannoside, $\beta$-methyl-D-xyloside, Lnorleucine, D-norvaline, L-norvaline, 1,8-octandiol, D-ornithine, phenoxyacetate, D-phenylalanine, phenylglycine, phenyllactate, phosphoenolpyruvate, phthalate, pimelate, poly-Dgalactomannan, polygalacturonate, D-proline, propionate, protocatechuate, putrescine, salicylamide, salicylate, sarcosine, sorbate, L-sorbose, spermine, suberate, D-tartrate, meso-tartrate, tartronate, taurine, thiamine, tricarballylate, trigonelline, tropate, tryptamine, D-tryptophan, L-tryptophan, tyramine, Ltyrosine, ureidosuccinate, $n$-valerate, isovalerate, L-valine, $x y-$ litol, and L-xylose.

The strains varied in their ability to utilize the following compounds as sole sources of carbon and energy, and these characteristics could not be used to differentiate hybridization groups: D-alanine, L-asparagine, L-aspartate, benzoate, fumarate, D-glucarate, D-glucosaminate, glycerate, glycerophosphate, glycine, glyoxylate, 4-hydroxybenzoate, 4-hydroxyphenylacetate, inulin, DL-isocitrate, DL-isoleucine, 2-ketoglutarate, L-lactate, D-lyxose, L-lyxose, L-malate, L-mannose, phenylpyruvate, $\mathrm{D}$-serine, spermidine, succinate, L-tartrate, L-threonine, and Dturanose.

The results of 44 biochemical tests that were used to differentiate the 11 DNA hybridization groups belonging to the genera Buttiauxella and Kluyvera in our numerical taxonomic study are shown in Table 2. The most useful tests for differentiating the 11 genomospecies with binary phenetic data are indicated. Hybridization groups 1 and 5 could not be distinguished on the basis of the results of any single test. These groups had to be distinguished on the basis of their overall biochemical profiles. Hybridization groups 3 and 6 could not be separated on the basis of the results of a single test, but could be differentiated on the basis of their $N$-acetyl-L-glutamine, adonitol, D-arabitol, L-fucose, mucate, and tartrate reactions. As stated above, these two pairs of hybridization groups exhibited the highest levels of interspecies DNA relatedness.

The probability distances that separated pairs of hybridization groups when the biochemical reaction results shown in Table 2 were used are shown in Table 3 . The probability distances for the 11 DNA hybridization groups varied from log 10.79 to $\log 57.77$. The lowest probability distances between hybridization groups in the same genus were log 15.46 for Buttiauxella hybridization groups 1 and 5 and $\log 10.79$ for Kluyvera hybridization groups 9 and 10 . The intergeneric probability distances ranged from log 23.16 to $\log 57.77$. Table 4 shows that the mean value for 21 phenotypic probability distances in the genus Buttiauxella was $\log 25.37$ (standard deviation, $\log 6.31$ ). The corresponding value for 21 DNA-DNA relatedness pairs (based on the relative binding ratios at $60^{\circ} \mathrm{C}$ shown in Table 6) was $53.49 \%$ (standard deviation, 5.69\%). The phenotypic and genomotypic values for DNA groups 7 and 2 correlate well; these values are the farthest from the mean values. The most typical DNA group could not be determined with certainty. Buttiauxella DNA group 5 exhibited the closest phenotypic probabilistic distance with other Buttiauxella DNA groups; however, DNA groups 3, 6, and 1 were the closest groups on the basis of DNA relatedness data.

The mean value for six total phenotypic probability distances in the genus Kluyvera was $\log 20.63$, and the standard deviation was $\log 8.37$. However, the mean value for 28 total phenotypic probability distances between the genera Buttiauxella and Kluyvera was log 37.06 (standard deviation, log 7.79). These high phenotypic probability distances indicate that there are significant differences between the genus Buttiauxella and the genus Kluyvera. Although these two genera have many similar phenotypic characteristics, the phenotypic data correlate with the DNA hybridization data and indicate that they are separate genera.

Previously reported conventional test results for Buttiauxella and Kluyvera strains are compared with the results obtained for other genera belonging to Enterobacteriaceae in Table 7 (11, 12,13 ). Although some biochemical characteristics can be used to differentiate various Buttiauxella and Kluyvera species ( $N$ acetyl-L-glutamate, $m$-coumarate, glycerol, 3-hydroxyphenylacetate, indole production, lactulose, lysine decarboxylase activity, melibiose, $\alpha$-methyl-D-glucopyranoside, raffinose, sucrose) (Table 2), no single biochemical test result differentiates these genera with 90 to $100 \%$ certainty. Nine test results (indole production, citrate utilization, L-arginine dihydrolase activity, ornithine decarboxylase activity, and fermentation of lactose, sucrose, raffinose, $\alpha$-methyl-D-glucopyranosidase, and melibiose) do give differences of 40 to $50 \%$ between Buttiauxella and Kluyvera species. The phenotypic probability distances between Buttiauxella and Kluyvera species and other genera that belong to the Enterobacteriaceae are shown in Table 5. These data are not identical to the data in Table 3 because they were calculated by using 47 conventional tests (12). The lowest probability distance $(\log 12.46)$ was the distance between the genus Buttiauxella and the genus Enterobacter. The probability distance between the genus Kluyvera and the genus Enterobacter was $\log 15.33$. It will be interesting to determine whether the probability distances correlate with relatedness trees generated from rRNA sequence similarity data.

On the basis of the biochemical and DNA hybridization data, we concluded that the genus Buttiauxella contains the following seven species: $B$. agrestis, species corresponding to previously described enteric groups 59, 63, and 64, and three previously undescribed species. The genus Kluyvera contains four species, $K$. ascorbata, $K$. cryocrescens, a species corresponding to Kluyvera unnamed species 3 (11), and a previously undescribed species. Taxonomic proposals to name and define the new species and to emend the description of $B$. agrestis are given below.

Emended description of Buttiauxella agrestis Ferragut, Izard, Gavini, Lefebvre, and Leclerc 1981. B. agrestis was called DNA hybridization group 1 in this study. The original description (13), which was based on the 17 strains originally described by Gavini et al. (15), stated that $60 \%$ of $B$. agrestis strains were malonate positive; we found (Table 2) that $96 \%$ of the strains were malonate positive. The biochemical tests that are useful for differentiating B. agrestis from other Buttiauxella species are the arginine dihydrolase, fucose, glycerol, lactose, melibiose, ornithine decarboxylase, palatinose, and D-sorbitol tests. This species has been isolated from mollusks, as well as water, soil, and humans.

Description of Buttiauxella ferragutiae sp. nov. Buttiauxella ferragutiae (fer'ra.gut.i.ae. M. L. fem. gen. n. ferragutiae, of Ferragut, in honor of Carmen Ferragut, a French microbiologist, 


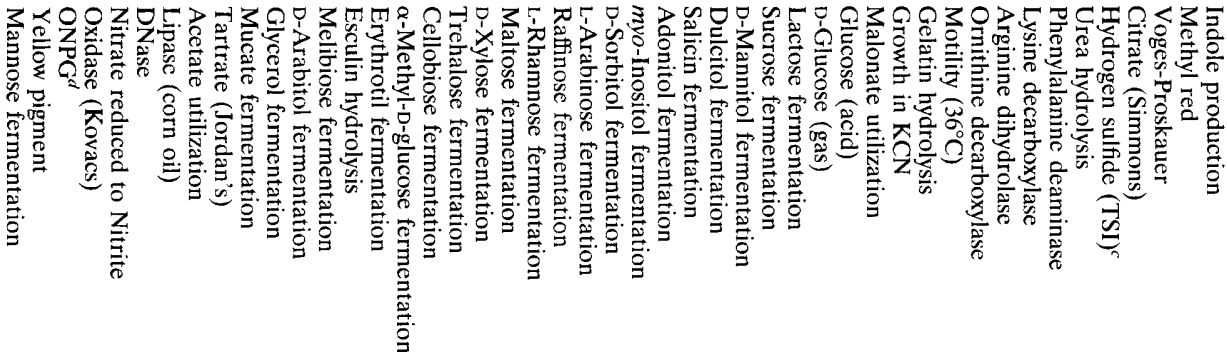

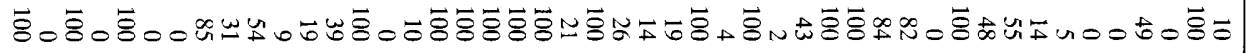

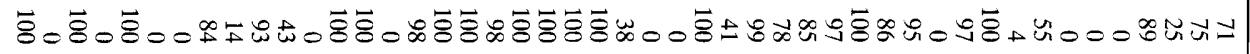
0

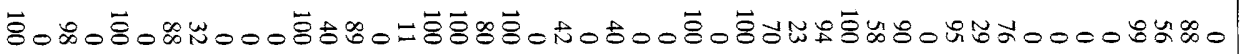

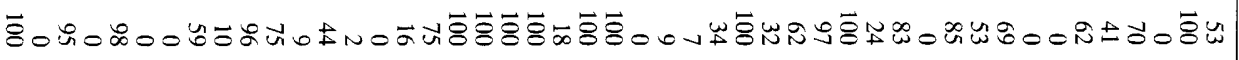

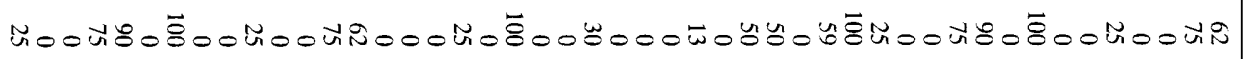

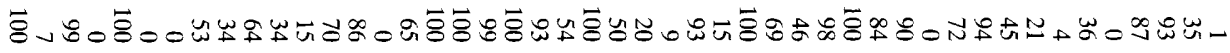

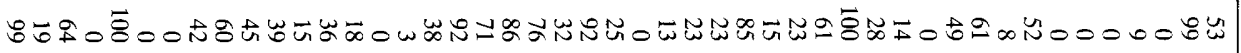

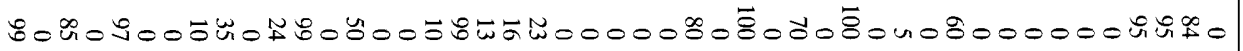

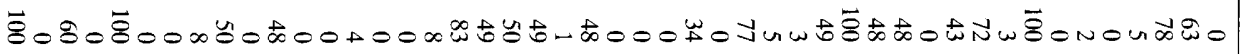

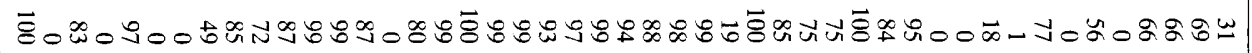

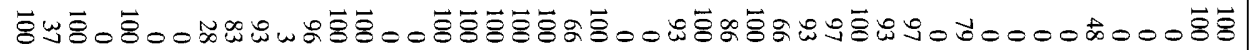

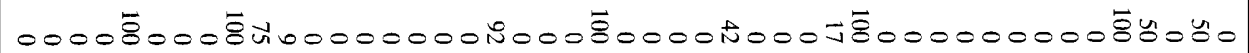

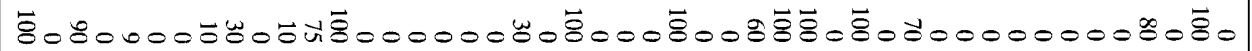

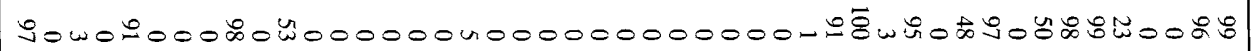

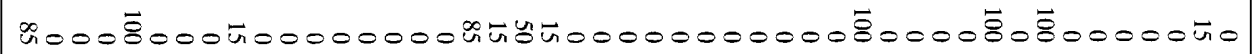

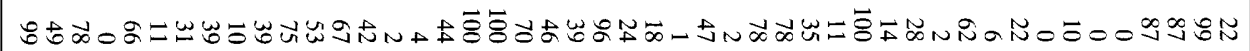
$0000 \overrightarrow{8} 00000000 \ddot{\infty} 000000000000$ m00000

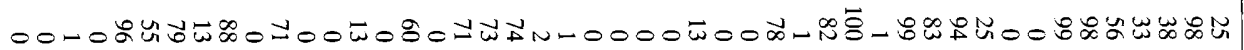

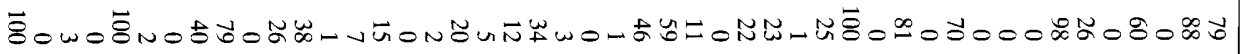

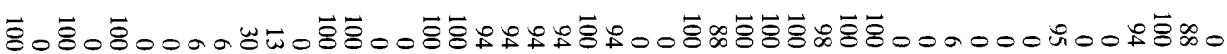

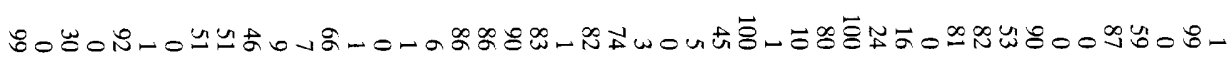

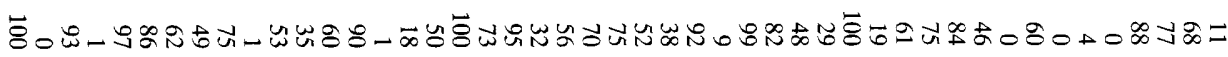

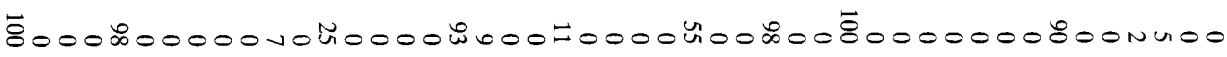

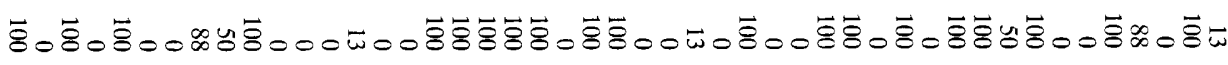

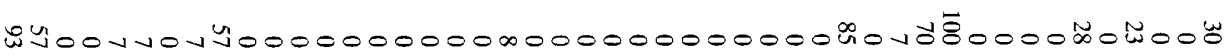

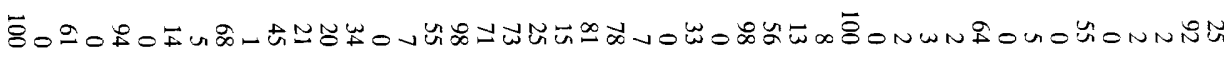

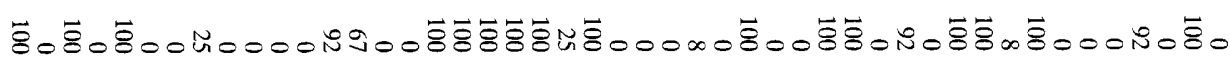


for her contribution to the study of the genus Buttiauxella [13]) was previously called enteric group $63(10,12)$ and in this study was referred to as DNA hybridization group 2. Biochemical characteristics are shown in Table 2. Positive lysine decarboxylase and D-sorbitol tests and negative ketogluconate and malonate tests clearly differentiate this species from all other Buttiauxella species. Isolated from water and soil. Because of the screening procedure, any strains present in mollusks would have been discarded; therefore, it is not known whether this species occurs in mollusks.

Description of the type strain. The type strain of $B$. ferragutiae is strain CDC 1180-81 (= CUETM 78-31 = ATCC 51602 $=$ DSM $9390=$ serial no. 054). This strain was isolated from unpolluted soil (13). Its colonies are circular, convex, greyish, and smooth on nutrient agar and blood agar. They are 1 to 2 $\mathrm{mm}$ in diameter after 1 day and 2 to $3 \mathrm{~mm}$ in diameter after 2 days. Good growth occurs at 30 to $36^{\circ} \mathrm{C}$. Weak, slow growth occurs at $42^{\circ} \mathrm{C}$. Biochemical characteristics are shown in Table 2.

Description of Buttiauxella gaviniae sp. nov. Buttiauxella gaviniae (ga.vin'i.ae. M. L. fem. gen. n. gaviniae, of Gavini, in honor of Françoise Gavini, a French microbiologist, for her contributions to the study of the genus Buttiauxella $[14,15])$ was previously called enteric group $64(10,12)$ and in this study was referred to as DNA hybridization group 3. Biochemical characteristics are shown in Table 2. Positive arginine dihydrolase, 5-ketogluconate, and palatinose reactions and negative ornithine decarboxylase and raffinose reactions are useful in differentiating $B$. gaviniae from other Buttiauxella species. A combination of reaction results is necessary to differentiate this species from Buttiauxella noackiae. All but one strain were isolated from mollusks.

Description of the type strain. B. gaviniae type strain S1/1984 (= ATCC $51604=$ DSM 9393 = serial no. 062) was isolated from a snail sampled in Braunschweig, Germany. Its colonies are circular, convex, greyish, and smooth on nutrient agar and blood agar. They are 1 to $2 \mathrm{~mm}$ in diameter after 1 day and 2 to $3 \mathrm{~mm}$ in diameter after 2 days at 30 to $36^{\circ} \mathrm{C}$. Grows poorly at $42^{\circ} \mathrm{C}$. The type strain has all of the characteristics given for the genus in Table 7 and for the species in Table 2.

Description of Buttiauxella brennerae sp. nov. Buttiauxella brennerae (bren'ner.ae. M. L. fem. gen. n. brennerae of Brenner, in honor of Frances W. Hickman-Brenner, an American microbiologist, for her contributions to the study of many genera of the Enterobacteriaceae $[4,9,10,16]$, including the description of the genus Kluyvera [11]) is referred to as DNA hybridization group 4 in this study. Biochemical characteristics are shown in Table 2. Tests that can be used to differentiate $B$. brennerae from other Buttiauxella species are the arabinose, arginine dihydrolase, fucose, myo-inositol, 5-ketogluconate, lysine decarboxylase, and malonate tests. Isolated from mollusks.

Description of the type strain. B. brennerae type strain S1/ 6-571 (= ATCC 51605 = DSM 9396 = serial no. 145) was isolated from a snail sampled in Braunschweig, Germany. Its colonies are circular, convex, greyish, and smooth on nutrient agar and blood agar. They are 1 to $2 \mathrm{~mm}$ in diameter after 1 day and 2 to $3 \mathrm{~mm}$ in diameter after 2 days. Good growth occurs at 30 to $36^{\circ} \mathrm{C}$, and no growth occurs at $42^{\circ} \mathrm{C}$. The type strain has all of the characteristics given for the genus in Table 7 and for the species in Table 2.

Description of Buttiauxella izardii sp. nov. Buttiauxella izardii (iz.ard'i.i. M. L. masc. gen. n. izardii, of Izard, in honor of Daniel Izard, a French microbiologist, for his contribution to the study of the genus Buttiauxella [13,14]) was referred to as DNA hybridization group 5 in this study. Biochemical characteristics are shown in Table 2. No single biochemical characteristic differentiates $B$. izardii from $B$. agrestis, but a combina- tion of several characteristics differentiates these taxa. Useful differential biochemical tests are the arabinose, citrate, fucose, myo-inositol, ornithine decarboxylase, and raffinose tests. Isolated from mollusks.

Description of the type strain. B. izardii type strain S3/2-161 (= ATCC 51606 = DSM 9397 = serial no. 151) was isolated from a snail sampled in Braunschweig, Germany. Its colonies are circular, convex, greyish, and smooth on nutrient agar and blood agar. They are 1 to $2 \mathrm{~mm}$ in diameter after 1 day and 2 to $3 \mathrm{~mm}$ in diameter after 2 days at 30 to $36^{\circ} \mathrm{C}$. Weak, slow growth occurs at $42^{\circ} \mathrm{C}$. The type strain has all of the biochemical characteristics given for the genus in Table 7 and for the species in Table 2.

Description of Buttiauxella noackiae sp. nov. Buttiauxella noackiae (no.ack'i.ae. M. L. fem. gen. n. noackiae, of Noack, in honor of Katrin Noack, who did most of the physiological tests at the Technische Universität Berlin and spent many years studying the usefulness of miniaturized automated tests for differentiation of various bacterial groups) was previously called enteric group $59(10,12)$ and in this study was referred to as DNA hybridization group 6. Biochemical characteristics of 15 strains isolated from snails are shown in Table 2. These characteristics are almost identical to those described for enteric group 59; the only exception is the result of the lactose test. All snail isolates lack a yellow pigment and are lactose negative, but seven of the eight enteric group 59 strains isolated from humans and food were lactose positive $(10,12)$. It is possible that there is a correlation between the ability to split and metabolize lactose and the ability to survive in humans. Tests that are useful in differentiating $B$. noackiae from other Buttiauxella species are the $N$-acetyl-L-glutamine, L-arginine dihydrolase, melibiose, and L-ornithine decarboxylase tests. In addition, $33 \%$ of the strains are phenylalanine deaminase positive and $40 \%$ produce indole. A combination of several characteristics is necessary to distinguish $B$. noackiae from other Buttiauxella species. Isolated from mollusks, human sputum, human wounds, and food. It is not known whether this species is pathogenic.

Description of the type strain. $B$. noackiae type strain NSW $11(=$ ATCC $51607=$ DSM $9401=$ serial no. 170), an EG59like strain, was isolated from a snail captured in Sydney, New South Wales, Australia. Good growth occurs at 30 to $36^{\circ} \mathrm{C}$. Strain NSW $11^{\mathrm{T}}$ colonies are circular, convex, greyish, and smooth on nutrient agar and blood agar, 1 to $2 \mathrm{~mm}$ in diameter after 1 day, and 2 to $3 \mathrm{~mm}$ in diameter after 2 days. Weak growth occurs at $42^{\circ} \mathrm{C}$. The type strain has all of the characteristics given for the genus in Table 7 and for the species in Table 2.

Description of Buttiauxella warmboldiae sp. nov. Buttiauxella warmboldiae (warm'bold.i.ae. M. L. fem. gen. warmboldiae, of Warmbold, in honor of Sabine Warmbold, who isolated most strains of the new Buttiauxella species at the Staatliches Medizinaluntersuchungsamt Braunschweig) was referred to as DNA hybridization group 7 in this study. Biochemical characteristics are shown in Table 2. myo-Inositol is utilized and acid is produced by freshly isolated strains for many months, in contrast to all other species belonging to the genera Buttiauxella and Kluyvera. However, these characteristics are lost after some years of storage; therefore, they are not constitutive. Other biochemical tests that are useful in differentiating $B$. warmboldiae from other Buttiauxella species are the arabinose, arginine dihydrolase, citrate, fucose, $\mathrm{KCN}$, malonate, maltitol, ornithine decarboxylase, and palatinose tests. As Table 3 shows, this species is the species that is the most distant from all other Buttiauxella species and has the highest phenotypic 
probability distance and the lowest level of DNA-DNA relatedness. Isolated from snails.

Description of the type strain. $B$. warmboldiae type strain NSW 326 (= ATCC 51608 = DSM 9404 = serial no. 182), an EG59-like strain, was isolated from a snail sampled in Sydney, New South Wales, Australia. Good growth occurs at 30 to $36^{\circ} \mathrm{C}$. Strain NSW $326^{\mathrm{T}}$ colonies are circular, convex, greyish, and smooth on nutrient agar and blood agar, 1 to $2 \mathrm{~mm}$ in diameter after 1 day, and 2 to $3 \mathrm{~mm}$ in diameter after 2 days. Moderate growth occurs at $42^{\circ} \mathrm{C}$. The type strain has all of the characteristics given for the genus in Table 7 and for the species in Table 2.

Description of Kluyvera cochleae sp. nov. Kluyvera cochleae (coch'le.ae. L. fem. gen. n. cochleae, of a snail) was referred to as DNA hybridization group 8 in this study. Generally less metabolically active than other Kluyvera species; e.g., the arabinose, $m$-coumarate, 3-hydroxyphenylacetate, lactulose, and 3-phenylpropionate reactions are negative. Negative for indole production and lysine decarboxylase activity. The negative methyl red reaction and positive Voges-Proskauer reaction distinguish $K$. cochleae from all Buttiauxella species and all other Kluyvera species. Other characteristics that differentiate $K$. cochleae from other Kluyvera species, as well as Buttiauxella species, are shown in Table $2 . K$. cochleae exhibits the largest probabilistic distance to other Kluyvera species (Tables 3 and 4. Isolated from mollusks.

Description of the type strain. $K$. cochleae type strain $\mathrm{S}$ 3/1-49 (= ATCC $51609=$ DSM $9406=$ serial no. 185) was isolated from a snail sampled in Braunschweig, Germany. Its colonies are circular, convex, greyish, and smooth on nutrient agar and blood agar. They are 1 to $2 \mathrm{~mm}$ in diameter after 1 day and 2 to $3 \mathrm{~mm}$ in diameter after 2 days at 30 to $36^{\circ} \mathrm{C}$. Moderate growth occurs at $42^{\circ} \mathrm{C}$. The type strain has all of the characteristics given for the genus in Table 7 and for the species in Table 2.

Description of Kluyvera georgiana sp. nov. Kluyvera georgiana (georg'i.a.na. M. L. fem. adj. georgiana, of Georgia, where important work on Buttiauxella and Kluyvera was done) was previously called Kluyvera species group 3 (11) and in this study was referred to as DNA hybridization group 9. The 3-phenylpropionate and $m$-coumarate reactions differentiate $K$. georgiana from $K$ cochleae. A combination of tests is necessary to differentiate $K$. georgiana from $K$. ascorbata and $K$. cryocrescens. Isolated from human sputum and throat cultures.

Description of the type strain. The type strain of $K$. georgiana is strain CDC 2891-76 (= ATCC $51603=$ DSM $9409=$ serial no. 189). It was isolated from human sputum (11). Good growth occurs at 30 to $42^{\circ} \mathrm{C}$. Strain CDC $2891-76^{\mathrm{T}}$ colonies are circular, convex, greyish, and smooth on nutrient agar and blood agar, 1 to $2 \mathrm{~mm}$ in diameter after 1 day, and 2 to $3 \mathrm{~mm}$ in diameter after 2 days. The type strain has all of the characteristics given for the genus in Table 7 and for the species in Table 2.

\section{REFERENCES}

1. Altwegg, M., A. von Graevenitz, and J. Zollinger-Iten. 1987. Medium and temperature dependence of decarboxylase reactions in Aeromonas spp. Curr. Microbiol. 15:1-4.
2. Altwegg, M., J. Zollinger-Iten, and A. von Graevenitz. 1986. Differentiation of Kluyvera cryocrescens from Kluyvera ascorbata by irgasan susceptibility testing. Ann. Microbiol. (Inst. Pasteur) 137A:159-168.

3. Brenner, D. J., G. R. Fanning, A. V. Rake, and K. E. Johnson. 1969. Batch procedure for thermal elution of DNA from hydroxyapatite. Anal. Biochem. 28:447-459.

4. Brenner, D. J., J. J. Farmer III, G. R. Fanning, A. G. Steigerwalt, P. Klykken, H. G. Wathen, F. W. Hickman, and W. H. Ewing. 1978. Deoxyribonucleic acid relatedness of Proteus and Providencia species. Int. J. Syst. Bacteriol. 28: 269-282.

5. Brenner, D. J., P. A. D. Grimont, A. G. Steigerwalt, G. R. Fanning, E. Ageron, and C. F. Riddle. 1993. Classification of citrobacteria by DNA hybridization: designation of Citrobacter farmeri sp. nov., Citrobacter youngae sp. nov., Citrobacter braakii sp. nov., Citrobacter werkmanii sp. nov., Citrobacter sedlakii sp. nov., and three unnamed Citrobacter genomospecies. Int. J. Syst. Bacteriol. 43:645-658.

6. Brenner, D. J., A. C. McWhorter, J. K. Leete-Knutson, and A. G. Steigerwalt. 1982. Escherichia vulneris: a new species of Enterobacteriaceae associated with human wounds. J. Clin. Microbiol. 15:1133-1140.

7. Dollberg, S., A. Gandacu, and A. Klar. 1990. Acute pyelonephritis due to a Kluyvera species in a child. Eur. J. Clin. Microbiol. Infect. Dis. 9:281-283.

8. Ewing, W. H. 1986. Edwards and Ewing's identification of Enterobacteriaceae, 4th ed. Elsevier, New York.

9. Farmer, J. J., III, M. A. Asbury, F. W. Hickman, D. J. Brenner, and the Enterobacteriaceae Study Group. 1980. Enterobacter sakazakii: a new species of "Enterobacteriaceae" isolated from clinical specimens. Int. J. Syst. Bacteriol. 30:569-584.

10. Farmer, J. J., III, B. R. Davis, F. W. Hickman-Brenner, A. McWhorter, G. P. Huntley-Carter, M. A. Asbury, C. Riddle, H. G. Wathen-Grady, C. Elias, G. R. Fanning, A. G. Steigerwalt, C. M. O'Hara, G. K. Morris, P. B. Smith, and D. J. Brenner. 1985. Biochemical identification of new species and biogroups of Enterobacteriaceae isolated from clinical specimens. J. Clin. Microbiol. 21:46-76.

11. Farmer, J. J., III, G. R. Fanning, G. P. Huntley-Carter, B. Holmes, F. W. Hickman, C. Richard, and D. J. Brenner. 1981. Kluyvera, a new (redefined) genus in the family Enterobacteriaceae: identification of Kluyvera ascorbata sp. nov. and Kluyvera cryocrescens sp. nov. in clinical specimens. J. Clin. Microbiol. 13:919-933.

12. Farmer, J. J., III, and M. T. Kelly. 1991. Enterobacteriaceae, p. 360-383. In A. Balows, W. J. Hausler, Jr., K. L. Herrmann, H. D. Isenberg, and H. J. Shadomy (ed.), Manual of clinical microbiology, 5th ed. American Society for Microbiology, Washington, D.C.

13. Ferragut, C., D. Izard, F. Gavini, B. Lefebvre, and H. Leclerc. 1981. Buttiauxella, a new genus of the family Enterobacteriaceae. Zentralbl. Bakteriol. Parasitenkd. Infektionskr. Hyg. Abt. 1 Orig. Reihe C 2:33-44.

14. Gavini, F., D. Izard, C. Ferragut, J. J. Farmer III, and H. Leclerc. 1983. Separation of Kluyvera and Buttiauxella by biochemical and nucleic acid methods. Int. J. Syst. Bacteriol. 33:880-882.

15. Gavini, F., B. Lefebvre, and H. Leclerc. 1976. Positions taxonomiques d'entérobactéries $\mathrm{H}_{2} \mathrm{~S}$-par rapport au genre Citrobacter. Ann. Microbiol. (Inst. Pasteur) 127A:275-295.

16. Hickman-Brenner, F. W., G. P. Huntley-Carter, Y. Saitoh, A. G. Steigerwalt, J. J. Farmer III, and D. J. Brenner. 1984. Moellerella wisconsensis, a new genus and species of Enterobacteriaceae found in human stool specimens. J. Clin. Microbiol. 19:460-463.

17. Luttrell, R. E., G. A. Rannick, J. L. Soto-Hernandez, and A. Verghese. 1988. Kluyvera species soft tissue infection: case report and review. J. Clin. Microbiol. 26:2650-2651.

18. Véron, M. 1975. Nutrition et taxonomie des enterobactéries. I. Methode d'étude des auxanogrammes. Ann. Microbiol. (Inst. Pasteur) 126A:267-274.

19. Wayne, L. G., D. J. Brenner, R. R. Colwell, P. A. D. Grimont, O. Kandler, M. I. Krichevsky, L. H. Moore, W. E. C. Moore, R. G. E. Murray, E. Stackebrandt, M. P. Starr, and H. G. Trüper. 1987. Report of the Ad Hoc Committee on Reconciliation of Approaches to Bacterial Systematics. Int. J. Syst. Bacteriol. 37:463-464. 